Supporting Information

\title{
Direct Observations of Segmental Dynamics at Polymer-Substrate Interface Enabled by Localizing Fluorescent Probes with Polymer Brushes
}

Yura Chung ${ }^{1 \dagger}$, Jieun Nam ${ }^{2 \dagger}$, Dongwan Son, ${ }^{2}$ Hyangseok Lee ${ }^{1}$, Myungwoong Kim*2, and Keewook Paeng*1

${ }^{1}$ Department of Chemistry, Sungkyunkwan University, Suwon 16419, Republic of Korea

${ }^{2}$ Department of Chemistry and Chemical Engineering, Inha University, Incheon 22212, Republic of Korea.

*Keewook Paeng: e-mail: paeng@skku.edu

*Myungwoong Kim: e-mail: mkim233@inha.ac.kr

${ }^{\dagger}$ Equal contribution 
(a)

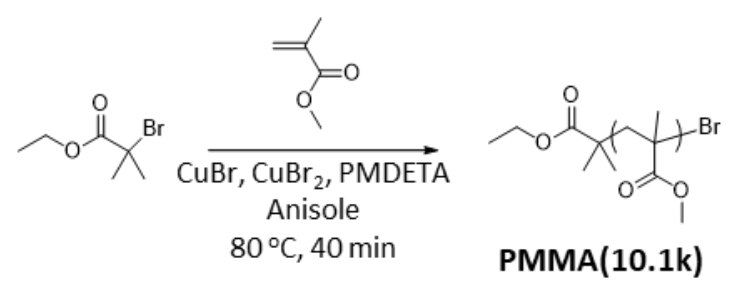

(b)

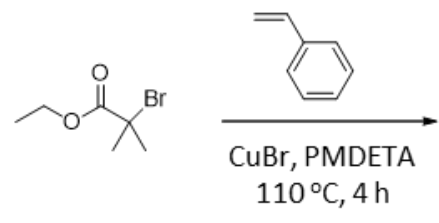<smiles>CCOC(=O)C(C)(C)CC(C)C(Br)c1ccccc1</smiles>

PS(9.1k)

Scheme S1. Synthesis of (a) PMMA and (b) PS using EBiB as an ATRP initiator.
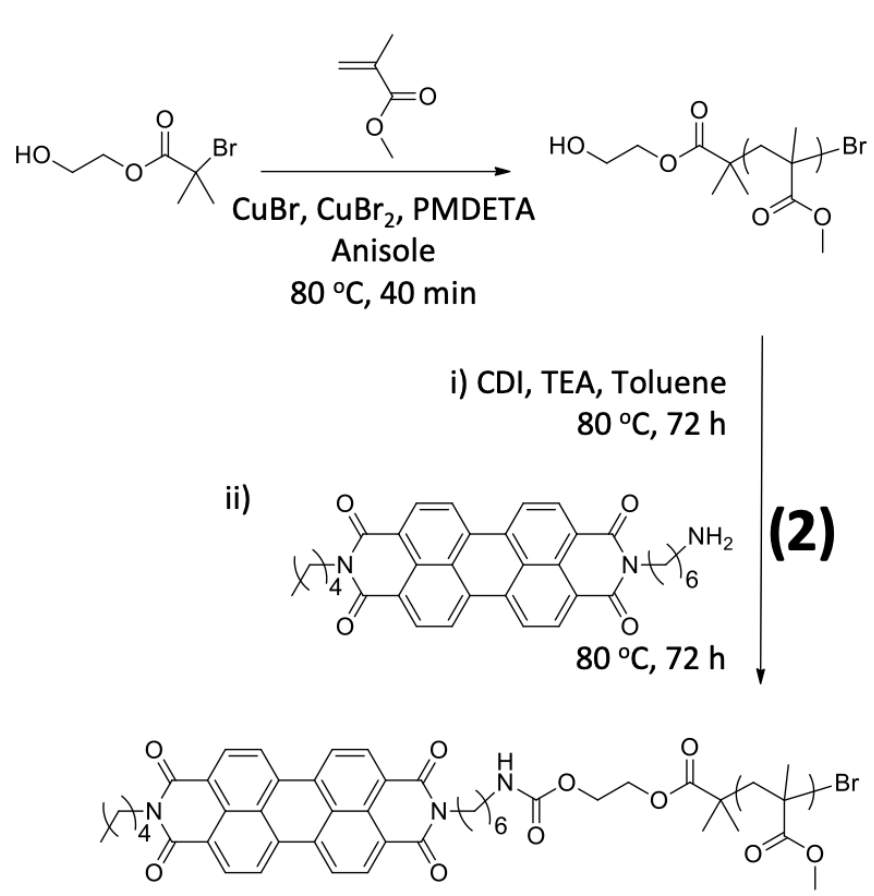

PDI-PMMA(9.1k)
(1)

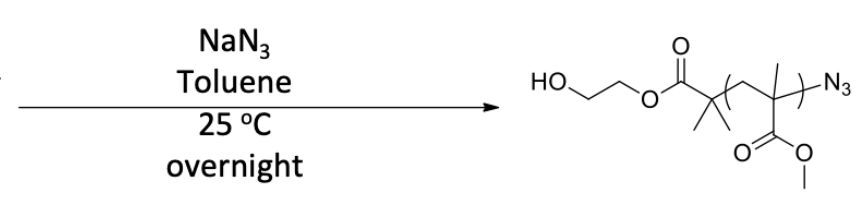

i) CDI, TEA, Toluene $80^{\circ} \mathrm{C}, 72 \mathrm{~h}$

ii)

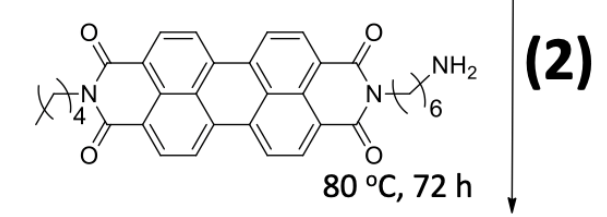

PDI-PMMA(9.3k)-N

Scheme S2. Synthesis of various heterotelechelic PMMA by (1) incorporation of azide group at the chain end for grafting on the surface, and (2) CDI coupling for attaching a fluorophore group. 
<smiles>CC(C)(Br)C(=O)OCCO</smiles>

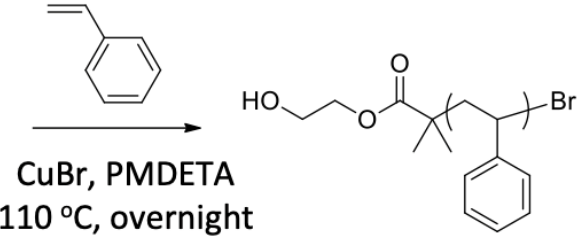

i) CDI, TEA, Toluene $80^{\circ} \mathrm{C}, 72 \mathrm{~h}$

ii)
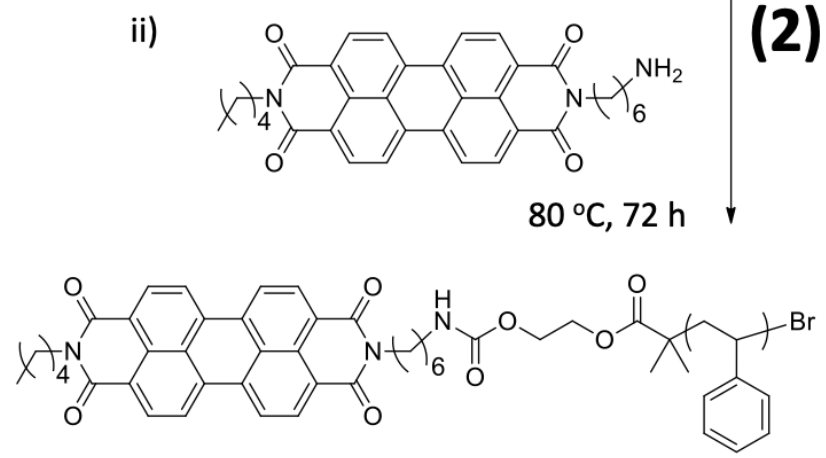

PDI-PS(10.1k)

(1)

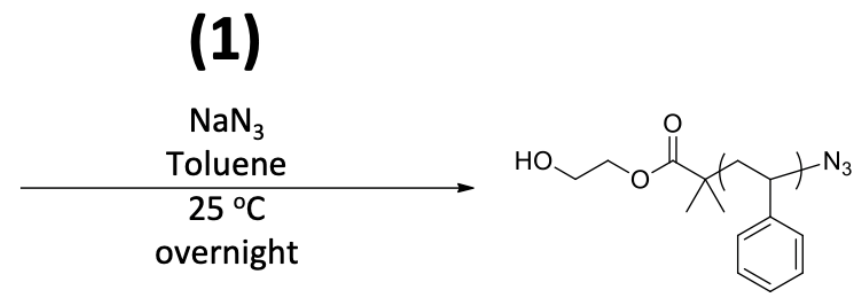

i) CDI, TEA, Toluene $80^{\circ} \mathrm{C}, 72 \mathrm{~h}$

(2) ii)

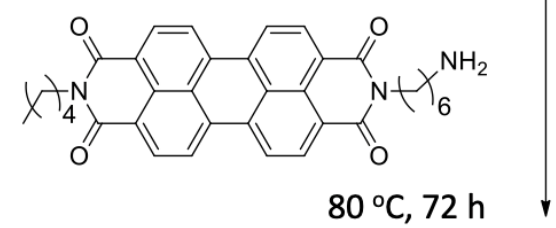

(2)

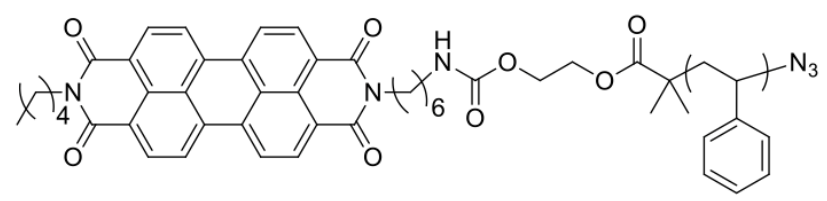

PDI-PS(9.3k)- $\mathbf{N}_{3}$

Scheme S3. Synthesis of various heterotelechelic PS by (1) incorporation of azide group at the chain end for grafting on the surface, and (2) CDI coupling for attaching a fluorophore group. 
Table S1. Characteristics of synthesized heterotelechelic polymers

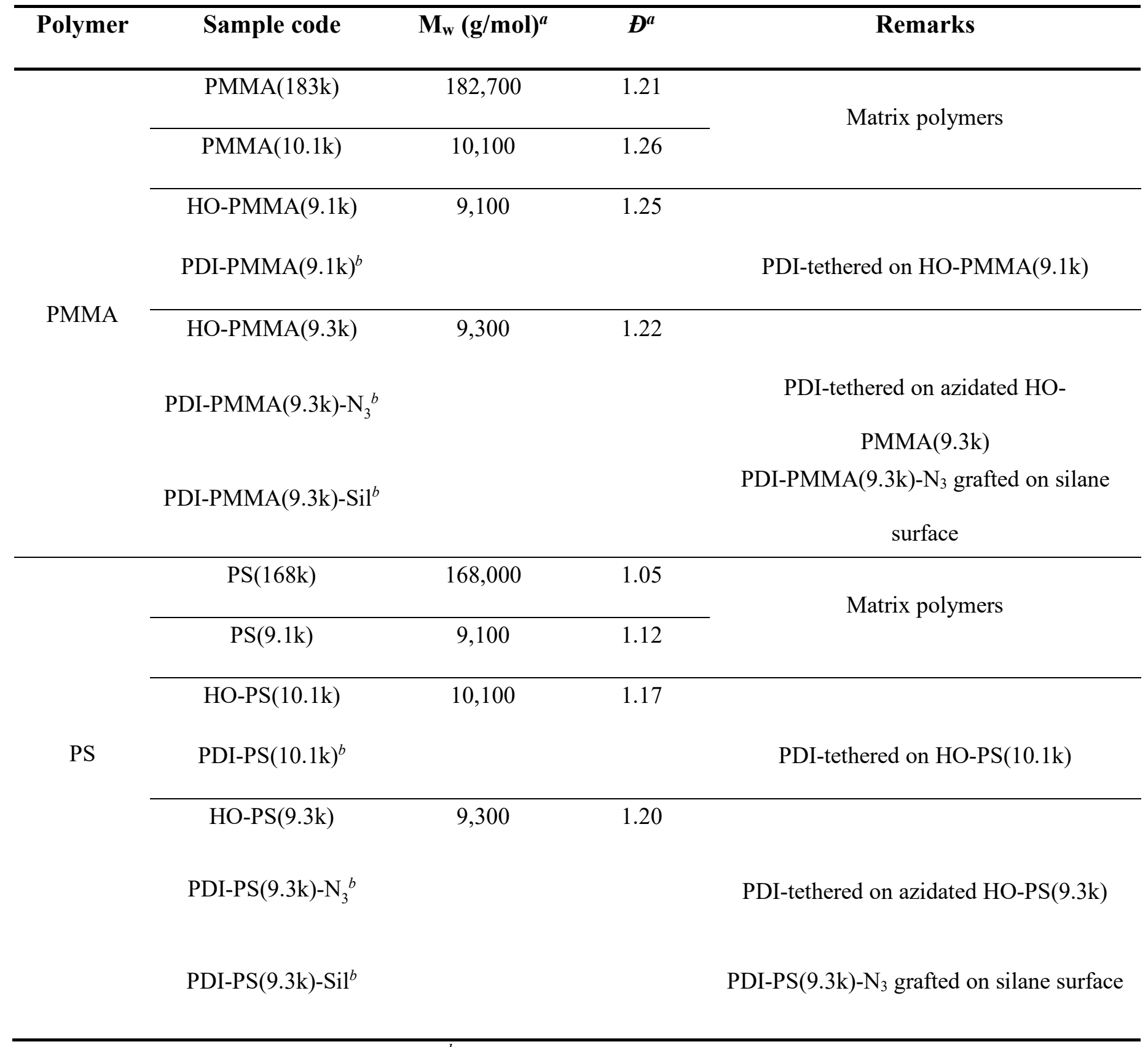

\footnotetext{
${ }^{a}$ Determined with SEC measurements; ${ }^{b}$ "PDI-" indicates tethered pPDI.
} 

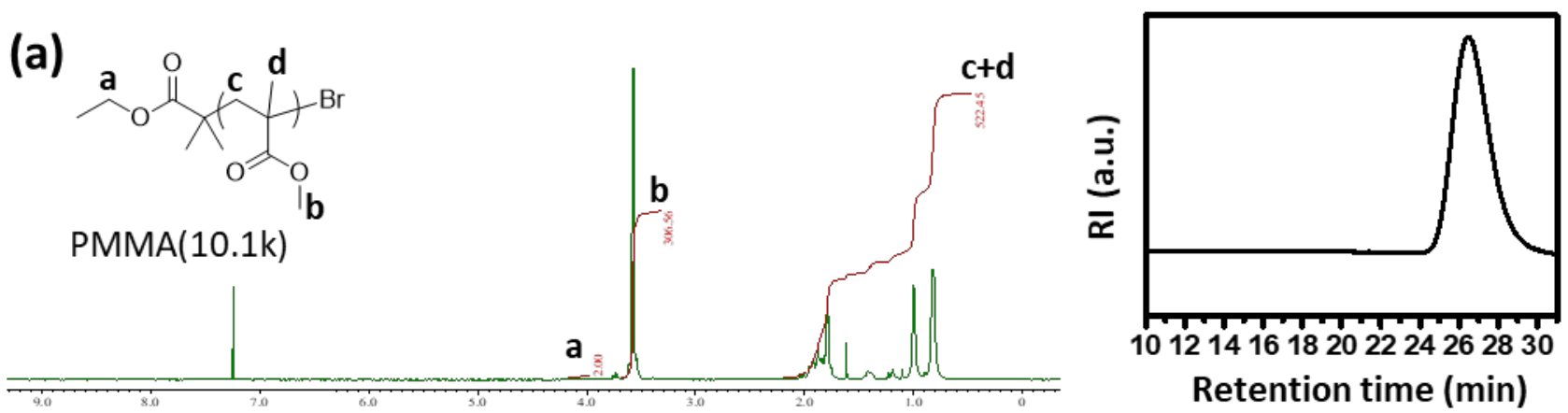
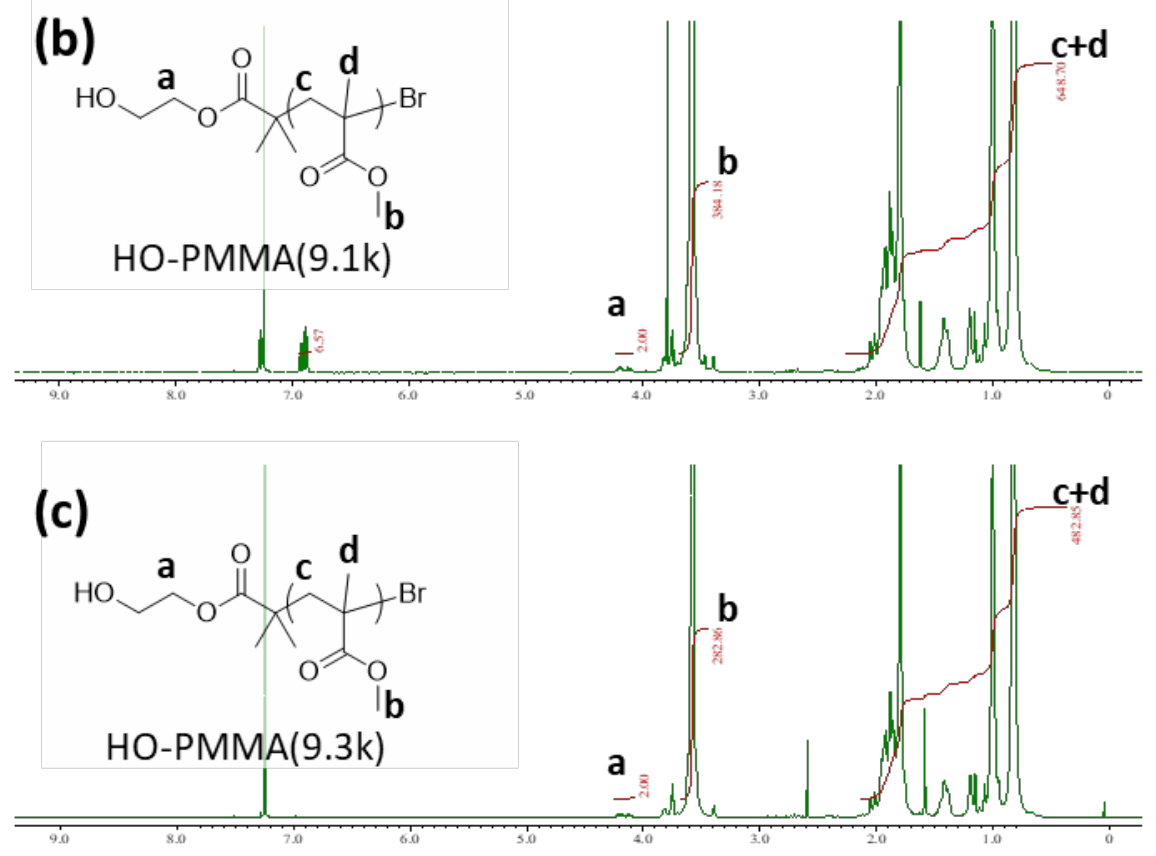
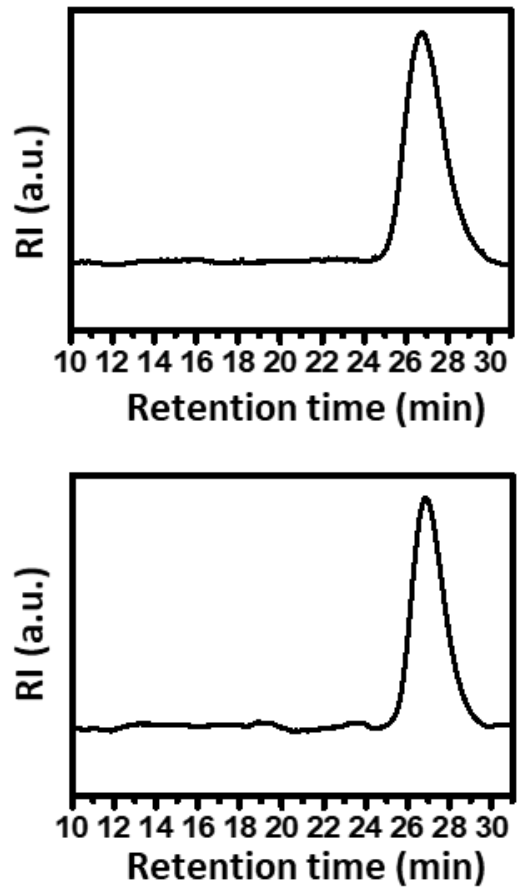

Figure S1. ${ }^{1} \mathrm{H}$ NMR spectra and SEC traces of synthesized poly(methyl methacrylate) samples using EBiB and HEBiB as an ATRP initiator. 
(a)
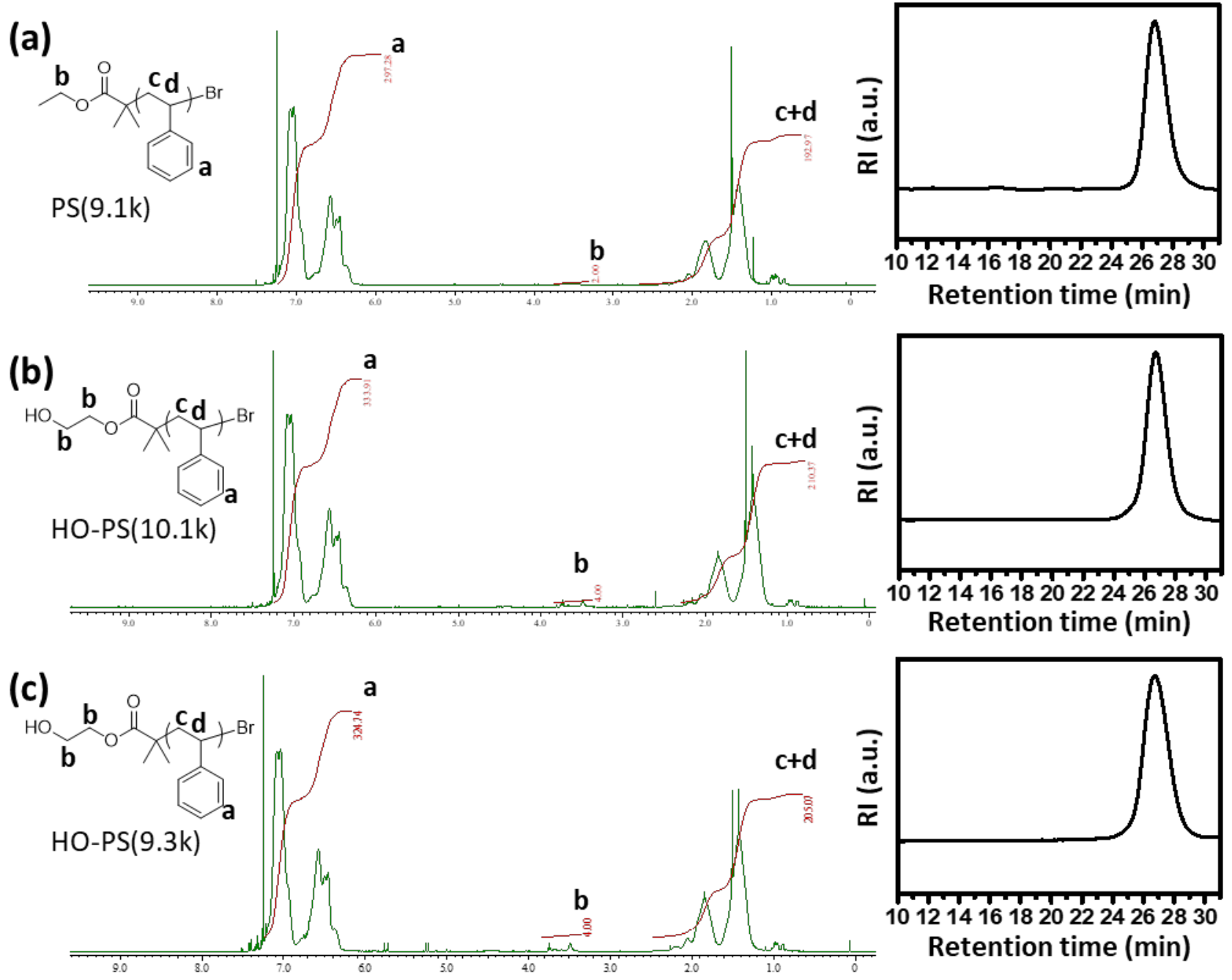

Figure S2. ${ }^{1} \mathrm{H}$ NMR spectra and SEC traces of synthesized polystyrene samples using EBiB and HEBiB as an ATRP initiator. 


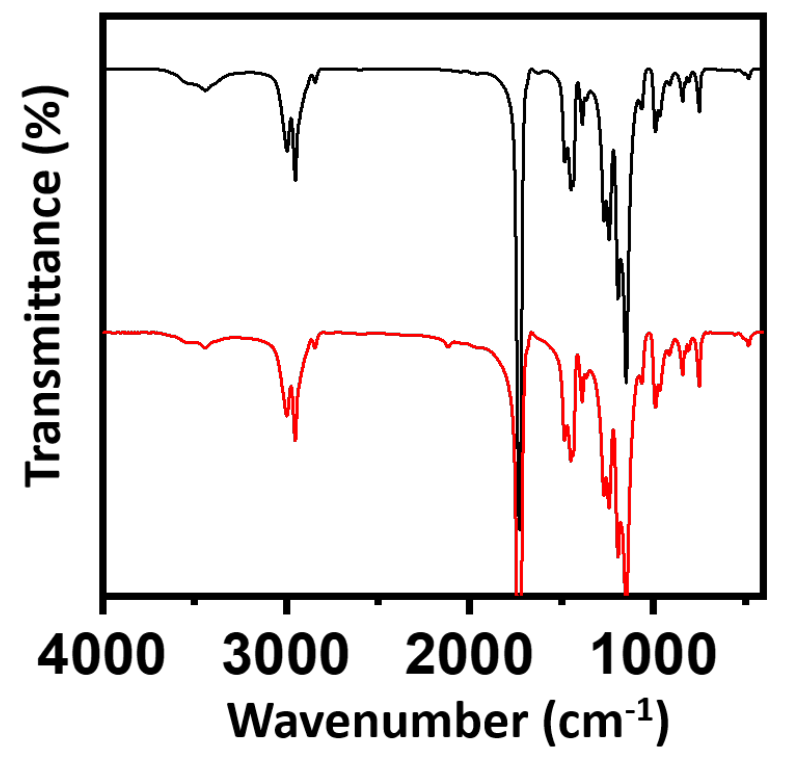

Figure S3. FT-IR spectra of HO-PMMA(9.3k) (black) and HO-PMMA-N 3 (red), which are typically observed from common PMMA samples, ${ }^{1}$ except for the peak at $2130 \mathrm{~cm}^{-1}$ confirming the successful incorporation of azide group at the chain end. 


\section{General procedure for the removal of untethered free PDI-NH $\mathrm{NH}_{2}$ in PDI-PS and PDI-PMMA samples}

SEC (Agilent Technologies, 1260 Infinity) equipped with both refractive index (RI) and UV/vis absorption detectors were used to study the presence of unreacted free PDI-NH $\mathrm{H}_{2}$ in PDI-PS and PDI-PMMA samples. For PDI$\mathrm{PS}(10 . \mathrm{k})$ sample, there was no unreacted free $\mathrm{PDI}-\mathrm{NH}_{2}$ in as-synthesized probe-tethered polymer/toluene solution (Figure S4). For PDI-PMMA(9.1k), the removal of untethered free probes was accomplished by fractionating aspolymerized samples and taking a fraction in the middle (Figure S5). Fractioning was performed by gradually adding non-solvent to the as-synthesized probe-tethered polymer/toluene solution and collecting precipitated samples by filtration when an appropriate amount of precipitation was formed. By repeating this process three more times, fractionated polymer samples were obtained. The precipitated samples were collected and dried at $100{ }^{\circ} \mathrm{C}$ under vacuum for $12 \mathrm{hrs}$, and were subjected to SEC analysis to measure molecular weight and to confirm the complete removal of untethered free probes. SEC used three columns (PLgel MIXED-C, PLgel MIXED-C, and PLgel MIXED-C, Waters) which were calibrated by polystyrene standard samples $(0.162-6,570 \mathrm{~kg} / \mathrm{mol}$, Agilent).

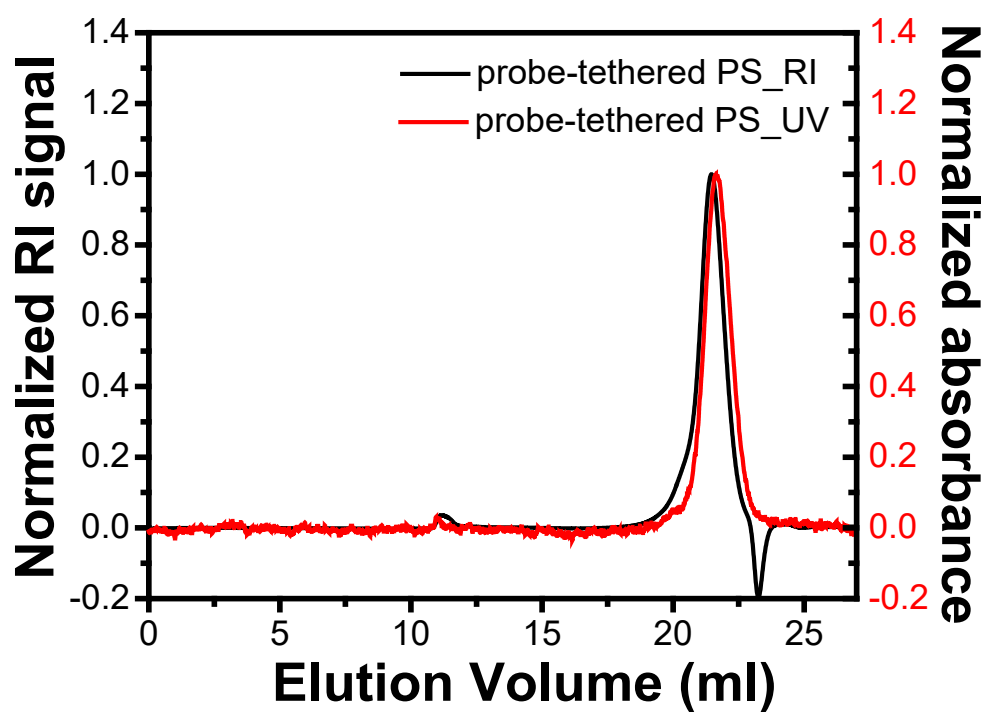

Figure S4. SEC chromatograms of PDI-PS(10.1k). No peak found at the low molecular weight region ensures that untethered free probes are removed. 


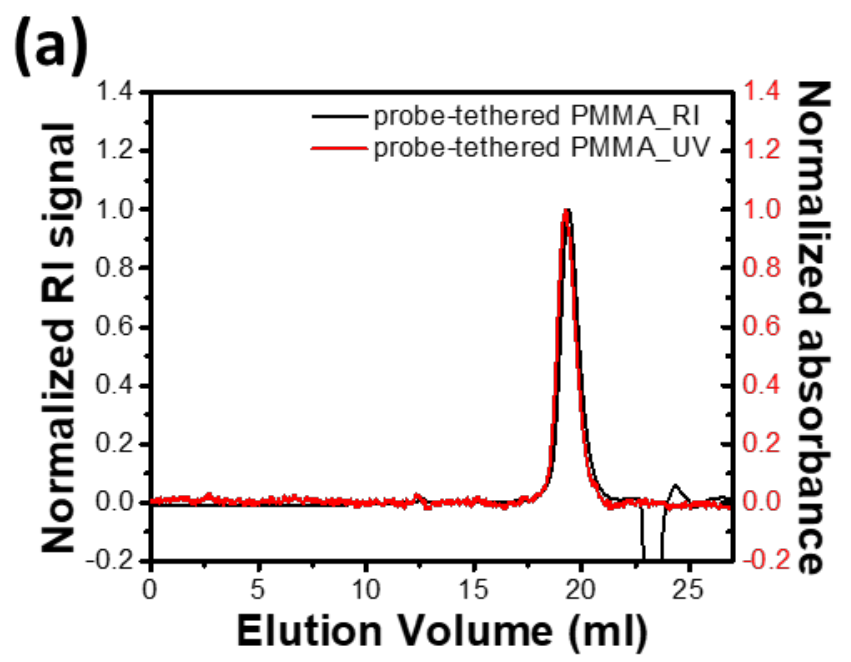

(b)

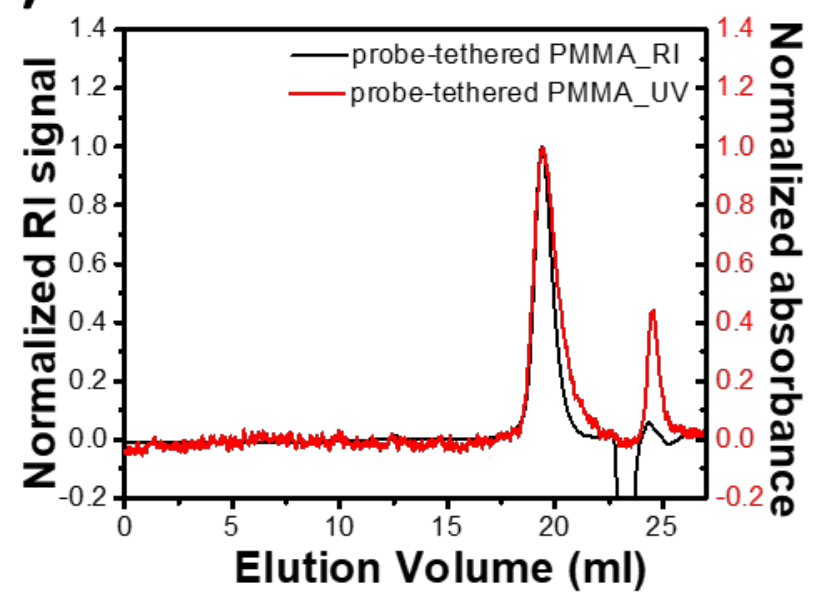

Figure S5. SEC chromatograms of PDI-PMMA(9.1k) (a) after the fractionation process, UV-/is absorption signals indicate complete removal of untethered free probes, and (b) as polymerized before the fractionation process which has the peak of untethered free probes traced by UV/vis detector. 

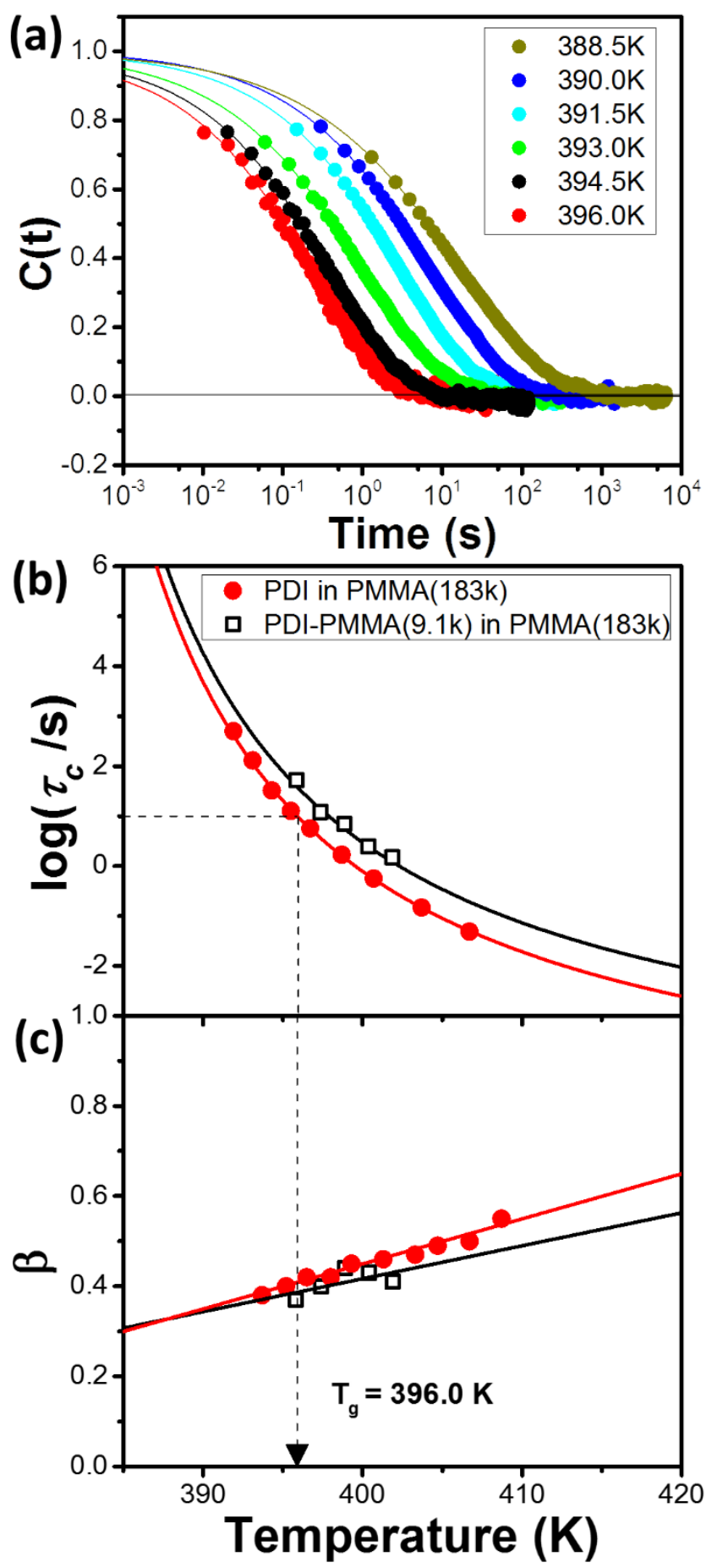

Figure S6. (a) Normalized autocorrelation decays of PDI-PMMA(9.1k) in PMMA(183k) for the indicated temperature measured by irFCM. Solid curves are best-fits to the stretched exponential function. Temperature dependences of (b) $\tau_{\mathrm{c}}$ and (c) $\beta$ for untethered free (pPDI) and PMMA-tethered probe (PDI-PMMA(9.1k)) in PMMA matrix. The vertical line indicates $T_{g}$ value defined by the temperature at $\tau_{\mathrm{c}}=10 \mathrm{~s}$ for the free probe in 
$\operatorname{PMMA}(183 k)$.

Figure S6a shows the normalized autocorrelation decays for PDI-PMMA(9.1k) in PMMA(183k) at different temperatures indicated. Autocorrelation decays faster at higher temperatures indicating probes rotating faster at elevated temperatures. The curved lines are fits to the stretched exponential function, $C(t)=C(0) \cdot \exp \left[-\left(t / \tau_{\mathrm{fit}}\right)^{\beta}\right]$ for the decays at the indicated temperatures and fit results are presented in Table S2. From the fit results of $\tau_{\text {fit }}$ and $\beta$, rotational correlation times $\left(\tau_{\mathrm{c}}\right)$ at each temperature were calculated using $\tau_{\mathrm{c}}=\left(\tau_{\mathrm{fit}} / \beta\right) \cdot \Gamma(1 / \beta)$ with $\Gamma$ represents the gamma function and plotted in Figure S6b. The curved lines in Figure S6b represent the Vogel-Fulcher-Tammann (VFT) equation $\left(\log \left(\tau / \tau_{0}\right)=\mathrm{B} /\left(\mathrm{T}-\mathrm{T}_{0}\right)\right)$ fit to the temperature dependence of rotational dynamics for free probe (pPDI) and vertical shift to match that of PMMA-tethered probe. Figure S6c shows the temperature dependence of $\beta$ for free (pPDI) and PMMA-tethered (PDI-PMMA(9.1k)) probes. The straight lines are linear fits to each data and $\beta s$ at $\mathrm{T}_{\mathrm{g}}$ are extracted from these fit lines.

Table S2. Temperature dependence of untethered free probe (pPDI) and tethered probes (PDI-PMMA) in PMMA matrices.

\begin{tabular}{c|ccccc}
\hline \multicolumn{1}{c}{ temp. } & $\boldsymbol{\tau}_{\mathbf{c}}(\mathbf{s e c})$ & $\boldsymbol{\tau}_{\text {fit }}(\mathbf{s e c})$ & $\boldsymbol{\beta}$ & $\begin{array}{c}\text { trajectory } \\
\text { length }\left(\boldsymbol{\tau}_{\text {fit}}\right)\end{array}$ \\
\hline \hline \multirow{2}{*}{ PPDI } & $384.3 \mathrm{~K}$ & 268.61 & 49.9 & 0.34 & 224.3 \\
in PMMA(10.1k) & $386.0 \mathrm{~K}$ & 46.17 & 12.04 & 0.39 & 265.8 \\
& $387.5 \mathrm{~K}$ & 15.80 & 3.83 & 0.37 & 313.1 \\
& $389.0 \mathrm{~K}$ & 5.06 & 1.60 & 0.41 & 300.6 \\
\hline \multirow{2}{*}{ PDI-PMMA(9.1k) } & $390.5 \mathrm{~K}$ & 2.40 & 0.77 & 0.41 & 313.2 \\
\hline \multirow{2}{*}{ in PMMA(10.1k) } & $387.0 \mathrm{~K}$ & 53.50 & 16.1 & 0.40 & 506.5 \\
& $388.5 \mathrm{~K}$ & 17.75 & 6.96 & 0.44 & 344.8 \\
& $391.5 \mathrm{~K}$ & 2.59 & 1.01 & 0.44 & 471.8 \\
& $393.0 \mathrm{~K}$ & 1.88 & 0.74 & 0.45 & 412.6 \\
& $394.5 \mathrm{~K}$ & 0.93 & 0.40 & 0.46 & 404.4 \\
\hline
\end{tabular}




\begin{tabular}{|c|c|c|c|c|c|}
\hline \multirow{5}{*}{$\begin{array}{l}\text { PDI-PMMA(9.1k) } \\
\text { in PMMA(183k) }\end{array}$} & $395.8 \mathrm{~K}$ & 52.37 & 12.52 & 0.37 & 516.1 \\
\hline & $397.4 \mathrm{~K}$ & 12.17 & 3.77 & 0.40 & 636.7 \\
\hline & $398.9 \mathrm{~K}$ & 5.96 & 2.31 & 0.44 & 707.5 \\
\hline & $400.4 \mathrm{~K}$ & 2.48 & 0.89 & 0.43 & 720.5 \\
\hline & $401.9 \mathrm{~K}$ & 1.49 & 0.47 & 0.41 & 509.5 \\
\hline \multirow{10}{*}{$\begin{array}{l}\text { PDI-PMMA(173k) } \\
\text { in PMMA(183k) }\end{array}$} & $393.7 \mathrm{~K}$ & 264.23 & 70.32 & 0.38 & 470.2 \\
\hline & $395.2 \mathrm{~K}$ & 71.51 & 21.00 & 0.40 & 563.9 \\
\hline & $396.5 \mathrm{~K}$ & 22.75 & 7.63 & 0.42 & 518.4 \\
\hline & $398.0 \mathrm{~K}$ & 8.52 & 2.98 & 0.42 & 538.9 \\
\hline & $399.3 \mathrm{~K}$ & 3.76 & 1.50 & 0.45 & 536.1 \\
\hline & $401.3 \mathrm{~K}$ & 1.39 & 0.59 & 0.46 & 539.4 \\
\hline & $403.3 \mathrm{~K}$ & 0.57 & 0.25 & 0.47 & 480.8 \\
\hline & $404.7 \mathrm{~K}$ & 0.26 & 0.12 & 0.49 & 453.5 \\
\hline & $406.7 \mathrm{k}$ & 0.13 & 0.06 & 0.50 & 516.3 \\
\hline & $408.7 \mathrm{~K}$ & 0.06 & 0.04 & 0.55 & 551.3 \\
\hline
\end{tabular}


Table S3. Temperature dependence of untethered free probe (pPDI) and tethered probe (PDI-PS) in PS matrices.

\begin{tabular}{|c|c|c|c|c|c|}
\hline & temp. & $\tau_{\mathrm{c}}(\mathrm{sec})$ & $\tau_{\mathrm{fit}}(\mathrm{sec})$ & $\beta$ & $\begin{array}{l}\text { trajectory } \\
\text { length }\left(\tau_{\text {fit }}\right)\end{array}$ \\
\hline \multirow{6}{*}{$\begin{array}{c}\text { pPDI } \\
\text { in PS(9.1k) }\end{array}$} & $366.2 \mathrm{~K}$ & 54.06 & 26.8 & 0.49 & 447.6 \\
\hline & $367.7 \mathrm{~K}$ & 15.84 & 6.54 & 0.45 & 612.0 \\
\hline & $369.2 \mathrm{~K}$ & 7.90 & 3.34 & 0.46 & 479.1 \\
\hline & $371.9 \mathrm{~K}$ & 2.37 & 0.90 & 0.44 & 712.1 \\
\hline & $373.4 \mathrm{~K}$ & 1.03 & 0.38 & 0.43 & 635.5 \\
\hline & $374.6 \mathrm{~K}$ & 0.50 & 0.24 & 0.50 & 490.1 \\
\hline \multirow{4}{*}{$\begin{array}{c}\text { PDI- } \\
\text { PS(10.1k) }\end{array}$} & $367.6 \mathrm{~K}$ & 30.57 & 15.6 & 0.51 & 612.0 \\
\hline & $369.1 \mathrm{~K}$ & 11.41 & 5.74 & 0.50 & 558.6 \\
\hline & $371.9 \mathrm{~K}$ & 2.96 & 1.25 & 0.46 & 639.5 \\
\hline & $373.4 \mathrm{~K}$ & 1.24 & 0.67 & 0.52 & 482.2 \\
\hline \multirow[t]{2}{*}{ in $\operatorname{PS}(9.1 k)$} & $374.9 \mathrm{~K}$ & 0.50 & 0.31 & 0.56 & 268.1 \\
\hline & $376.4 \mathrm{~K}$ & 0.20 & 0.12 & 0.56 & 406.8 \\
\hline \multirow{4}{*}{$\begin{array}{c}\text { PDI- } \\
\text { PS(10.1k) }\end{array}$} & $375.9 \mathrm{~K}$ & 38.67 & 19.88 & 0.51 & 603.3 \\
\hline & $377.4 \mathrm{~K}$ & 14.47 & 7.71 & 0.52 & 518.5 \\
\hline & $379.0 \mathrm{~K}$ & 6.15 & 3.68 & 0.55 & 434.1 \\
\hline & $380.5 \mathrm{~K}$ & 2.06 & 1.18 & 0.54 & 541.9 \\
\hline \multirow[t]{2}{*}{ in $P S(168 k)$} & $382.1 \mathrm{~K}$ & 0.87 & 0.52 & 0.56 & 457.6 \\
\hline & $383.6 \mathrm{~K}$ & 0.41 & 0.18 & 0.47 & 434.3 \\
\hline
\end{tabular}


Table S4. Temperature dependence of dye tethered PMMA brush in PMMA matrices.

\begin{tabular}{|c|c|c|c|c|c|}
\hline & temp. & $\tau_{\mathrm{c}}(\mathrm{sec})$ & $\tau_{\text {fit }}(\mathrm{sec})$ & $\boldsymbol{\beta}$ & $\begin{array}{c}\text { trajectory } \\
\text { length }\left(\tau_{\mathrm{fit}}\right)\end{array}$ \\
\hline \multirow{5}{*}{$\begin{array}{l}\text { PDI-PMMA(9.3k)-Sil } \\
\text { in PMMA(10.1k) }\end{array}$} & $388.22 \mathrm{~K}$ & 26.59 & 7.17 & 0.38 & 557.8 \\
\hline & $389.72 \mathrm{~K}$ & 9.11 & 2.85 & 0.41 & 557.1 \\
\hline & $391.22 \mathrm{~K}$ & 3.70 & 1.13 & 0.40 & 564.3 \\
\hline & $392.72 \mathrm{~K}$ & 1.51 & 0.56 & 0.43 & 430.5 \\
\hline & $394.23 \mathrm{~K}$ & 0.78 & 0.32 & 0.45 & 262.6 \\
\hline \multirow{5}{*}{$\begin{array}{l}\text { PDI-PMMA(9.3k)-Sil } \\
\text { in PMMA(183k) }\end{array}$} & $394.72 \mathrm{~K}$ & 214.02 & 24.05 & 0.31 & 598.7 \\
\hline & $396.22 \mathrm{~K}$ & 46.01 & 8.15 & 0.40 & 537.4 \\
\hline & $397.72 \mathrm{~K}$ & 21.11 & 6.75 & 0.37 & 502.1 \\
\hline & $399.22 \mathrm{~K}$ & 5.68 & 1.81 & 0.41 & 353.8 \\
\hline & $400.72 \mathrm{~K}$ & 2.29 & 0.72 & 0.40 & 442.4 \\
\hline
\end{tabular}


Table S5. Temperature dependence of dye tethered PS brush in PS matrices.

\begin{tabular}{|c|c|c|c|c|c|}
\hline & temp. & $\tau_{\mathrm{c}}(\mathrm{sec})$ & $\tau_{\text {fit }}(\sec )$ & $\boldsymbol{\beta}$ & $\begin{array}{c}\text { trajectory } \\
\text { length }\left(\tau_{\text {fit }}\right)\end{array}$ \\
\hline \multirow{6}{*}{$\begin{array}{l}\text { PDI-PS(9.3k)-Sil } \\
\text { in } \operatorname{PS}(9.1 k)\end{array}$} & $366.44 \mathrm{~K}$ & 82.17 & 37.54 & 0.47 & 369.8 \\
\hline & $367.94 \mathrm{~K}$ & 39.72 & 17.36 & 0.47 & 368.7 \\
\hline & $369.44 \mathrm{~K}$ & 14.90 & 7.26 & 0.49 & 330.3 \\
\hline & $370.94 \mathrm{~K}$ & 5.58 & 2.82 & 0.50 & 424.7 \\
\hline & $372.45 \mathrm{~K}$ & 2.64 & 1.29 & 0.49 & 370.7 \\
\hline & $373.94 \mathrm{~K}$ & 1.55 & 0.54 & 0.43 & 459.8 \\
\hline \multirow{5}{*}{$\begin{array}{l}\text { PDI-PS(9.3k)-Sil } \\
\text { in PS(168k) }\end{array}$} & $375.32 \mathrm{~K}$ & 49.15 & 21.45 & 0.47 & 447.6 \\
\hline & $376.84 \mathrm{~K}$ & 25.52 & 8.58 & 0.42 & 466.3 \\
\hline & $378.33 \mathrm{~K}$ & 6.97 & 2.91 & 0.46 & 549.2 \\
\hline & $379.84 \mathrm{~K}$ & 2.57 & 1.30 & 0.50 & 616.7 \\
\hline & $381.34 \mathrm{~K}$ & 0.95 & 0.48 & 0.50 & 648.9 \\
\hline
\end{tabular}


Table S6. Vogel-Fulcher-Tammann (VFT) equation $\left(\log \left(\tau / \tau_{0}\right)=\mathrm{B} /\left(\mathrm{T}-\mathrm{T}_{0}\right)\right)$ fit values.

\begin{tabular}{|c|c|c|c|c|c|}
\hline Host polymer & Probe & $\log \left(\tau_{0}\right)$ & B & $\mathbf{T}_{\mathbf{0}}$ & Vertical shift* \\
\hline PMMA(183k) & $\begin{array}{c}\text { pPDI } \\
\text { PDI-PMMA(9.1k) }\end{array}$ & -5.31 & $120.46 \mathrm{~K}$ & $376.80 \mathrm{~K}$ & $\begin{array}{c}0 \\
0.50\end{array}$ \\
\hline PMMA(10.1k) & $\begin{array}{c}\text { pPDI } \\
\text { PDI-PMMA(9.1k) }\end{array}$ & -4.08 & $89.62 \mathrm{~K}$ & $370.41 \mathrm{~K}$ & $\begin{array}{c}0 \\
0.30\end{array}$ \\
\hline $\operatorname{PS}(168 k) * *$ & $\begin{array}{c}\text { pPDI } \\
\text { PDI-PS(10.1k) }\end{array}$ & -10.50 & $414.15 \mathrm{~K}$ & $341.30 \mathrm{~K}$ & $\begin{array}{c}0 \\
0.30\end{array}$ \\
\hline $\operatorname{PS}(9.1 \mathrm{k})$ & $\begin{array}{c}\text { pPDI } \\
\text { PDI-PS(10.1k) }\end{array}$ & -21.42 & $1863.16 \mathrm{~K}$ & $285.30 \mathrm{~K}$ & $\begin{array}{c}0 \\
0.30\end{array}$ \\
\hline
\end{tabular}

* Vertical shift values are relative to the VFT fits to the free probe temperature dependence.

** VFT equation fit values are from the fit to the dielectric relaxation data of PS. The fit values of dielectric relaxation data were $\log \left(\tau_{0}\right)=-11.25, \mathrm{~B}=414.15 \mathrm{~K}$, and $\mathrm{T}_{0}=341.30 \mathrm{~K}$, and vertical shift for the pPDI probe were 0.75 . 


\section{(a) Randomly dispersed polymer-tethered probe film}
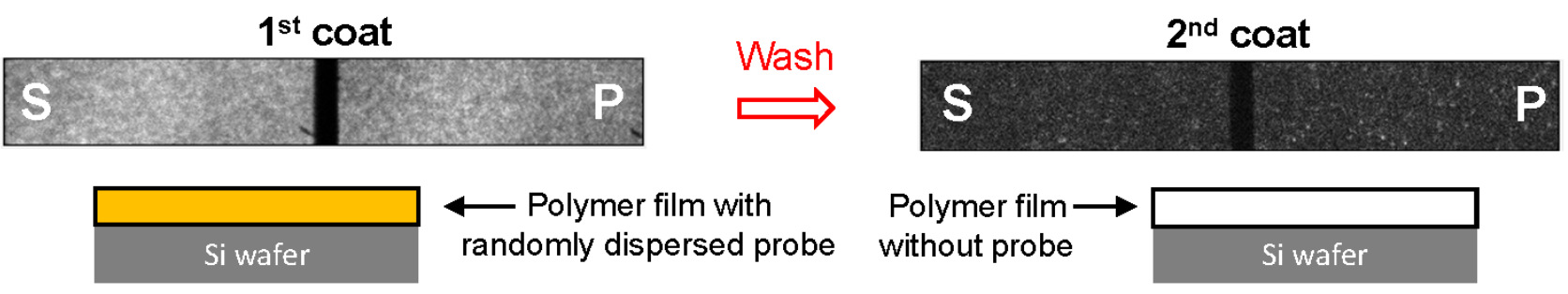

(b) Probe-tethered polymer brush film

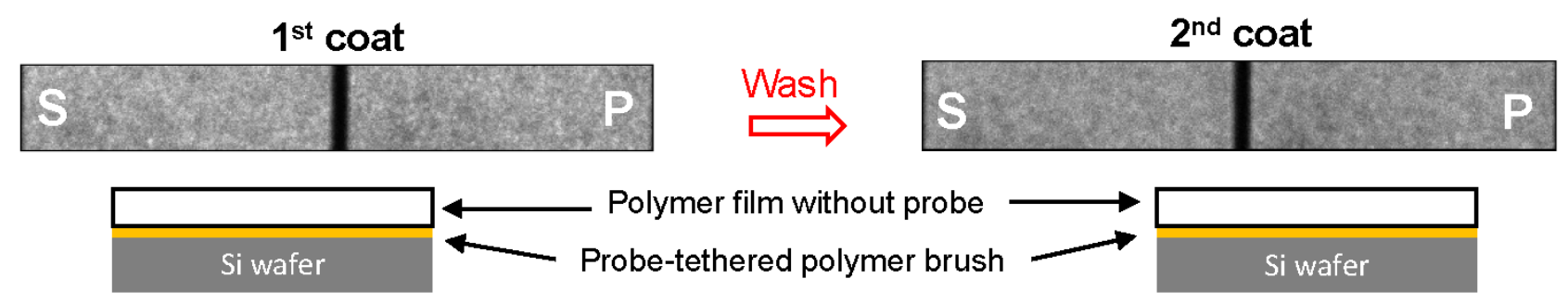

Figure S7. Fluorescence images of (a) Randomly dispersed polymer-tethered probe film and (b) probe-tethered polymer brush film before and after stripping of the $1^{\text {st }}$ coat and applying the $2^{\text {nd }}$ coat. Each image is separated into $\mathrm{s}$ and $\mathrm{p}$ polarized images by Wollaston prism.

To check the potential detachment of the polymer brush, we compared the fluorescence images of (a) randomly dispersed polymer-tethered probe film with those of (b) probe-tethered polymer brush film before and after stripping of the $1^{\text {st }}$ coat and applying the $2^{\text {nd }}$ coat. All the spin-coated films were $\approx 200 \mathrm{~nm}$ and, except the $1^{\text {st }}$ coat of (a) randomly dispersed polymer-tethered probe film, contained no fluorescent probe in the spin-coated films. All the prepared films were annealed at $\mathrm{T}_{\mathrm{g}}+20 \mathrm{~K}$ for at least $12 \mathrm{~h}$ under vacuum $(\approx 10 \mathrm{mTorr})$ prior to acquiring images and performing rotation measurements. Stripping of the $1^{\text {st }}$ coat was done by putting the sample in a clean toluene solution for at least $12 \mathrm{~h}$ to swell the polymer film and sonicating for at least $2 \mathrm{~h}$. This process was repeated at least two more times. For the sample with (a) randomly dispersed polymer-tethered probe, the stripping process decreased the fluorescence intensity to $1 / 10$ of the $1^{\text {st }}$ coat which is close to the intensity expected with a polymer film with no fluorescent probes whereas the fluorescent intensity of (b) probe-tethered brush film was found to be similar to that of the $1^{\text {st }}$ coat within the error range $(\approx 12 \%)$ confirming the integrity of the probe-tethered polymer brush grafted onto the substrate.

The rotation measurements of the $2^{\text {nd }}$ coated (b) probe-tethered polymer brush film were performed and compared to those of the $1^{\text {st }}$ coated film. Figure S8 shows that the temperature dependences of the rotational correlation times obtained from the $1^{\text {st }}$ and $2^{\text {nd }}$ coat films are almost identical. $1^{\text {st }}$ coat measurement data are the 
reproduction of the brush result in Figure 5 (filled squares) of the manuscript.

(a)

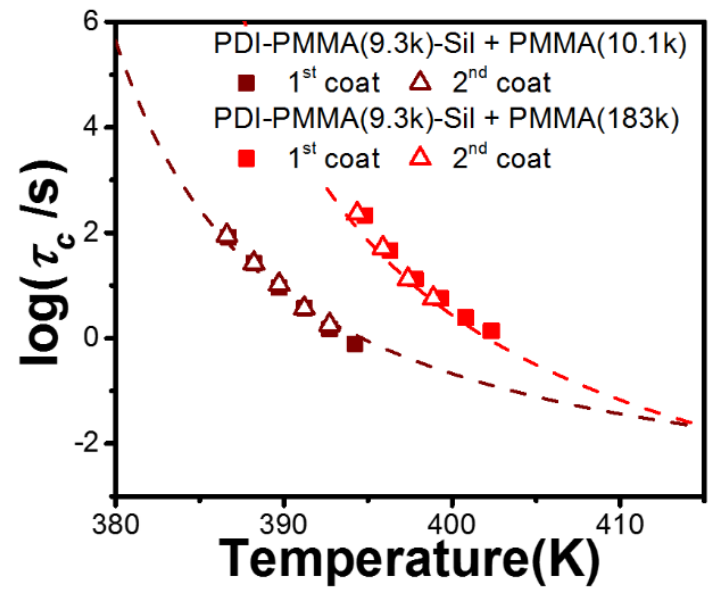

(b)

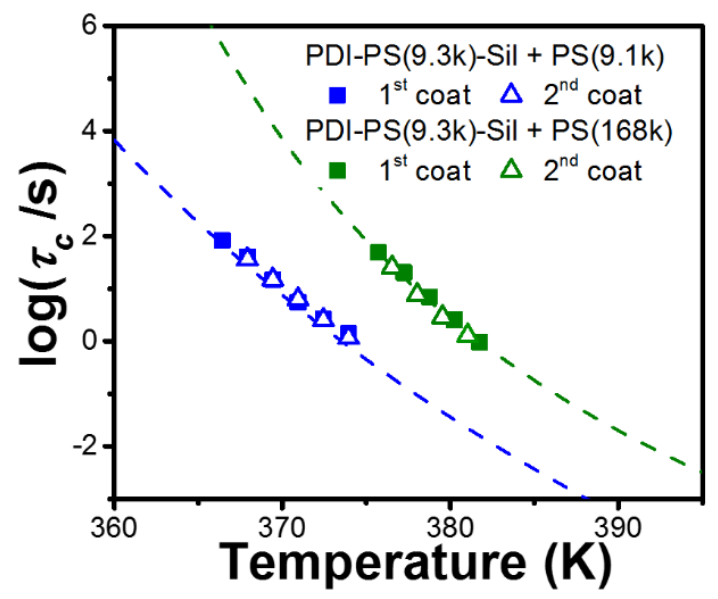

Figure S8. Temperature dependences of $\tau_{\mathrm{c}}$ for probe-tethered polymer brushes covered with bulk films without probe before and after stripping of the $1^{\text {st }}$ coat and applying the $2^{\text {nd }}$ coat for different molecular weight bulk films of (a) PMMA and (b) PS. 


\section{Reference}

1. Odziomek, M.; Bahri, M.; Boissiere, .; Sanchez, C.; Lassalle-Kaiser, B.; Zitolo, A.; Ersen, O; Nowak, S.; Tard, C.; Giraud, M.; Faustini, M.; Peron, J. Aerosol synthesis of thermally stable porous noble metals and alloys by using bi-functional templates. Mater. Horiz. 2020, 7, 541-550. 